\title{
Special Issue: Sustainable Development of Energy, Water and Environment Systems
}

\author{
Andreas Kallioras • Nikola Ruzinski
}

Received: 20 July 2011 / Accepted: 20 July 2011 /

Published online: 3 August 2011

(C) Springer Science+Business Media B.V. 2011

\section{Preface}

The 5th Dubrovnik Conference on Sustainable Development of Energy, Water and Environment Systems (held in 2009) was attended by 307 scientists from 55 countries and 6 continents. The majority of the participants focused on methods, policies and technologies for increasing the sustainability of development, while always considering the economic, environmental and social aspects involved. With special reference to water science, the presented articles considered the link of both pillars of the conference (i.e. water and energy) all under the prism of environmental sustainability. The selected papers mainly discuss state-of-the-art water resources management issues which refer to applied international approaches and policies. Among others, they discuss water resources management issues in the framework of the European Water Framework Directive (WFD) 2000/60/EC, advanced technologies in the field of wastewater treatment (WWT) as well as engineering water works for water storage techniques and methodologies.

Water Framework Directive 2000/60/EC is considered as one of the most important legislative enactments -within the context of European environmental law and policy- with respect to the management and protection of water resources within the European region. Bilaletdin et al., use steady state and dynamic modeling approach in order to assess the impacts of different loading scenarios of water quality of Lake Onega, the second largest lake in Europe, as demanded by the WFD. Martinez et al., assuming that the physical laws are called to be the objective and universal tools to assess water costs, developed Physical Hydronomics $(\mathrm{PH})$ as the accounting tool for the WFD application, regarding its physicochemical objectives.

\footnotetext{
A. Kallioras $(\bowtie)$

Institute of Applied Geosciences, Hydrogeology Group, Technical University of Darmstadt, Darmstadt, Germany e-mail: kallioras@geo.tu-darmstadt.de e-mail: kallioras@metal.ntua.gr

N. Ruzinski

Faculty of Mechanical Engineering and Naval Architecture, Department of Energy, Power Engineering and Environment, University of Zagreb, Zagreb, Croatia e-mail: Nikola.ruzinski@fsb.hr
} 
Iterative procedure can be used in order to solve problems of flow distribution per pipe in water distributive looped pipelines. Brkic uses a number of iterative methods (such as, Hardy Cross, Modified Hardy Cross, Node-Loop method, Modified Node method and M. M. Andrijašev method) for the determination of hydraulic solution of pipeline networks.

Increasing world population results in higher wastewater quantities and therefore the need for improvement of wastewater treatment plant efficiency becomes a necessity; especially in overpopulated countries. Khosravi et al., study the suitability of nanofiltration in purification of the discharge water from external activated sludge processes in the pulp and paper industry for reuse in the paper manufacturing process. Teixeira et al., provide an evaluation of the Natural Organic Matter, NOM, removals by three different treatment sequences (one conventional and two non-conventional), and the molecular weight distribution of the treated waters by High Performance Size Exclusion Chromatography, HPSEC, and the Disinfection By-Products, DBPs, formation potential.

Water reservoirs are essential engineering works for the development of a community as they can be used to retain significant water quantities which can be preferably distributed in time and space. As this issue, is more pronounced in semi- and arid regions Krol et al., study an area in NE Brazil in order to show that the effect of small reservoirs on water availability from large reservoirs may be significant, and increase both in relative and absolute sense under unfavorable climate change. Shuka et al., propose management strategies to improve the water use efficiency with particular reference to eutrophication through their advanced limnological survey of a man-made reservoir in Albania.

As energy is considered one of the most important pillars for the development of a country; geothermal energy is a field of investigation which, especially in Europe, always gains interest. In their paper, Kurevija and Vulin, discuss the prospects of energy balance with more efficient methods of energy resources exploitation with respect to high enthalpy geothermal potential of deep gas fields. Oldmeadow et al., discuss and analyze some major applications of geothermal energy in high profile public buildings within urban settings.

Acknowledgments This special issue has resulted from selected papers which were presented in the 5th Dubrovnik Conference on Sustainable Development of Energy, Water and Environment Systems. We would to acknowledge the efforts of the authors and reviewers for their contribution to this special issue but also all researchers, water managers and other experts who participated in our conference. Andreas Kallioras would also like to personally thank Prof. Neven Duic for his guidance and support during the development of this special issue. 